\title{
Synthesis, Crystal structure, and Magnetic Properties of Dinuclear Iron(III) Complexes with Methoxo Bridges
}

\author{
Jong Won Shin, ${ }^{\dagger}$ Jeong Hyeong Han, Sankara Rao Rowthu, ${ }^{\dagger}$ Bong Gon Kim,${ }^{\ddagger}$ and Kil Sik Min* \\ Department of Chemistry Education, Kyungpook National University, Daegu 702-701, Korea. ${ }^{*}$ E-mail: minks@knu.ac.kr \\ ${ }^{\dagger}$ Department of Chemistry, Kyungpook National University, Daegu 702-701, Korea \\ ${ }^{\ddagger}$ Department of Chemistry Education, Gyeongsang National University, Jinju 660-701, Korea \\ Received August 27, 2010, Accepted October 4, 2010
}

\begin{abstract}
The reaction of stoichiometric amount of $\mathrm{FeCl}_{2} \cdot 4 \mathrm{H}_{2} \mathrm{O}$, (2-pyridylmethyl, 3-pyridylmethyl)amine (2,3-pyma) and sodium azide/sodium thiocyanate in methanol under aerobic conditions affords the dinuclear Fe(III) complexes, [(2,3-pyma) $\left(\mathrm{N}_{3}\right)_{2} \mathrm{Fe}\left(\mu-\mathrm{OCH}_{3}\right)_{2} \mathrm{Fe}\left(\mathrm{N}_{3}\right)_{2}(2,3$-pyma) $] \cdot \mathrm{CH}_{3} \mathrm{OH}(1)$ and $\left[(2,3 \text {-pyma })(\mathrm{NCS})_{2} \mathrm{Fe}(\mu \text {-OCH })_{2}\right)_{2} \mathrm{Fe}(\mathrm{NCS})_{2}(2,3-$ pyma $\left.)\right]$ (2) in good yield. Two bis-methoxy-bridged diiron(III) complexes are isolated and characterized. The coordination geometries around iron(III) ions in $\mathbf{1}$ and $\mathbf{2}$ are the same tetragonally distorted octahedron. The iron(III) ions are coordinated by two nitrogens of a 2,3-pyma, two nitrogens of two azide/thiocyanate ions, and two oxygens of two methoxy groups. Both compounds are isomorphous. The structures of $\mathbf{1}$ and $\mathbf{2}$ display the $\mathrm{C}-\mathrm{H} \cdots \pi$ and/or $\pi$ - $\pi$ stacking interactions as well as hydrogen bonding interactions, respectively. Compounds $\mathbf{1}$ and $\mathbf{2}$ show significant antiferromagnetic couplings through the bridged methoxy groups between the iron(III) ions in the temperature range from 5 to $300 \mathrm{~K}\left(H=-2 J S_{1} \cdot S_{2}, J=-19.1\right.$ and $-13.9 \mathrm{~cm}^{-1}$ for $\mathbf{1}$ and 2 ).
\end{abstract}

Key Words: Iron(III) complex, Ligand, Crystal structure, Stacking interactions, Magnetic properties

\section{Introduction}

The design and synthesis of discrete multinuclear metal complexes continue to be a research area of increasing importance due to the structural elucidation of metal centers in biomimetic model for metalloenzymes and the potential applications such as molecule-based magnetism and redox catalysis. ${ }^{1}$ Among these studies, many iron(III) and copper(II) dinuclear complexes with bis( $\mu$-alkoxo)-bridged linkages have been investigated, in order to characterize the superexchange couplings via the alkoxo ligands between the metal ions. ${ }^{2}$ For examples, the diiron(III) complexes, $\left[\mathrm{PH}(t-\mathrm{Bu})_{3}\right]_{2}\left[\mathrm{Fe}_{2}(\mu-\mathrm{OEt})_{2} \mathrm{Cl}_{6}\right]$ and $\mathrm{Fe}_{2}$ (pesd) $\left(\mu-\mathrm{OCH}_{3}\right)_{2} \mathrm{Cl}_{2}$, have been shown the antiferromagnetic interactions with coupling constants $(J)$ of -24.6 and $-16.3 \mathrm{~cm}^{-1}$, respectively (pesd $=1,4$-piperazinediylbis $(N$-ethylenesalicylaldiminato) $).{ }^{3}$ Furthermore, a bis( $\mu$-alkoxo)-bridged dinuclear iron (III) complex with a tripodal N3O ligand, $\left[\mathrm{Fe}(\mathrm{pmha})\left(\mathrm{NO}_{3}\right)_{2}\right]_{2}$ $\left(\mathrm{NO}_{3}\right)_{2}(\mathrm{Hpmha}=\mathrm{N}, \mathrm{N}$-bis(2-pyridylmethyl)- $N$-(2-hydroxyethyl)amine), was prepared as a biomimetic model for the dioxygenase enzymes and showed the intradiol-cleaving dioxygenase activity. ${ }^{4}$ Very recently, a tetranuclear iron(III) complex bridged with methoxy groups and azide ions has been prepared and interestingly it showed both ferromagnetic and antiferromagnetic interactions within the discrete unit. ${ }^{5}$ In this context, we tried to explore to make discrete iron(III) dinuclear complexes bridged with end-on azide ions displaying a ferromagnetic coupling. Unexpectedly, we have obtained two bis $\left(\mu-\mathrm{OCH}_{3}\right)$-bridged iron (III) dinuclear complexes, not the sought end-on azido-bridged diiron(III) complexes, i.e., [(2,3-pyma) $\left(\mathrm{N}_{3}\right)_{2} \mathrm{Fe}\left(\mu-1,1-\mathrm{N}_{3}\right)_{2} \mathrm{Fe}$ $\left(\mathrm{N}_{3}\right)_{2}$ (2,3-pyma)]. Herein, we report the synthesis, crystal structures, and magnetic properties of bis $\left(\mu-\mathrm{OCH}_{3}\right)$-bridged iron(III) dinuclear complexes, [(2,3-pyma) $\left(\mathrm{N}_{3}\right)_{2} \mathrm{Fe}\left(\mu-\mathrm{OCH}_{3}\right)_{2} \mathrm{Fe}\left(\mathrm{N}_{3}\right)_{2}$ (2,3-pyma) $] \cdot \mathrm{CH}_{3} \mathrm{OH}(\mathbf{1})$ and $\left[(2,3\right.$-pyma $)(\mathrm{NCS})_{2} \mathrm{Fe}\left(\mu-\mathrm{OCH}_{3}\right)_{2}$
$\mathrm{Fe}(\mathrm{NCS})_{2}$ (2,3-pyma)] (2), prepared from the reaction of $\mathrm{FeCl}_{2}$. $4 \mathrm{H}_{2} \mathrm{O}, 2,3$-pyma, and $\mathrm{NaN}_{3} / \mathrm{NaSCN}$ in methanol.

\section{Experimental Section}

Materials and measurements. All chemicals and solvents used in the syntheses were of reagent grade and were used without further purification. (2-pyridylmethyl, 3-pyridylmethyl)amine (2,3-pyma, $\mathrm{C}_{12} \mathrm{H}_{12} \mathrm{~N}_{3}$ ) was prepared by a literature method. ${ }^{6} \mathrm{In}-$ frared spectra were recorded with a ThermoFisher Scientific IR200 FT-IR spectrometer $\left( \pm 1 \mathrm{~cm}^{-1}\right)$. Elemental analyses were performed by the analytical laboratory of Kyungpook National University. Magnetic susceptibilities were measured in an applied field of 5000 Oe between 5 and $300 \mathrm{~K}$ on a Quantum Design MPMS superconducting quantum interference device (SQUID) magnetometer. Diamagnetic corrections were made by using Pascal's constants (522 (1) and $486 \times 10^{-6} \mathrm{emu} / \mathrm{mol}(\mathbf{2})$ ).

Preparation of $\left[(2,3-p y m a)\left(\mathrm{N}_{3}\right)_{2} \mathrm{Fe}\left(\mu-\mathrm{OCH}_{3}\right)_{2} \mathrm{Fe}\left(\mathrm{N}_{3}\right)_{2}(2,3-\right.$ pyma)] $\cdot \mathrm{CH}_{3} \mathrm{OH}$ (1). To a $\mathrm{MeOH}$ solution $(10 \mathrm{~mL})$ of $\mathrm{FeCl}_{2}$. $4 \mathrm{H}_{2} \mathrm{O}(50 \mathrm{mg}, 0.25 \mathrm{mmol})$ was added dropwise a $\mathrm{MeOH}$ solution (10 mL) of (2-pyridylmethyl, 3-pyridylmethyl)amine (2,3pyma, $50 \mathrm{mg}, 0.25 \mathrm{mmol}$ ), and the color became dark red, and the solution was stirred for $30 \mathrm{~min}$ at room temperature. A $\mathrm{MeOH}$ solution $(10 \mathrm{~mL})$ of sodium azide $(33 \mathrm{mg}, 0.51 \mathrm{mmol})$ was added to the mixture solution and the solution was allowed to stir for $2 \mathrm{~h}$. Red precipitates of $\mathbf{1}$ formed that collected by filtration and washed with methanol, and dried in air. Yield: $70 \mathrm{mg}(69 \%)$. Single crystals of 1 suitable for X-ray crystallography were obtained from a DMF/MeOH (v/v, 1:4) mixture solution. IR (KBr) 3378, 3253, 2941, 2916, 2818, 2070, 2047, $1608,1342,1031 \mathrm{~cm}^{-1}$. Anal. Calcd for $\mathrm{C}_{28} \mathrm{H}_{40} \mathrm{Fe}_{2} \mathrm{~N}_{18} \mathrm{O}_{4}$ : C, 41.81; H, 5.01; N 31.34. Found: C, 41.49; H, 4.77; N, 31.00.

Preparation of $\left[(2,3-p y m a)(\mathrm{NCS})_{2} \mathrm{Fe}\left(\mu-\mathrm{OCH}_{3}\right)_{2} \mathrm{Fe}(\mathrm{NCS})_{2}\right.$ 
(2,3-pyma)] (2). To a MeOH solution $(10 \mathrm{~mL})$ of $\mathrm{FeCl}_{2} \cdot 4 \mathrm{H}_{2} \mathrm{O}$ (50 mg, $0.25 \mathrm{mmol}$ ) was added dropwise a $\mathrm{MeOH}$ solution (10 $\mathrm{mL}$ ) of 2,3-pyma ( $50 \mathrm{mg}, 0.25 \mathrm{mmol}$ ), and the color became dark red, and the solution was stirred for $30 \mathrm{~min}$ at room temperature. A MeOH solution $(10 \mathrm{~mL})$ of sodium thiocyanate (41 $\mathrm{mg}, 0.51 \mathrm{mmol}$ ) was added to the mixture solution and the solution was allowed to stir for $2 \mathrm{~h}$. Red precipitates of $\mathbf{2}$ formed that collected by filtration and washed with methanol, and dried in air. Yield: $53 \mathrm{mg}$ (49\%). Single crystals of 2 suitable for X-ray crystallography were obtained from a DMF/MeOH (v/v, 1:4) mixture solution. IR (KBr) 3203, 3129, 2953, 2887, 2819, 2035,2012 (sh), 1607, 1480, $1034 \mathrm{~cm}^{-1}$. Anal. Calcd for $\mathrm{C}_{32} \mathrm{H}_{40}-$ $\mathrm{Fe}_{2} \mathrm{~N}_{10} \mathrm{~S}_{4} \mathrm{O}_{4}$ : C, 44.24; H, 4.64; N 16.12; S, 14.77. Found: C, 44.26; H, 4.34; N, 16.16; S, 14.27.

$\mathrm{X}$-ray crystallographic data collection and refinement. Single crystals of $\mathbf{1}$ and $\mathbf{2}$ were mounted on a Bruker SMART APEX CCD-based diffractometer (Korea Basic Science Institute, Chonju Branch). X-ray data for 1 and 2 were collected at 173(2) $\mathrm{K}$ and using Mo K $\alpha$ radiation $(\lambda=0.71073 \AA$, graphite monochromator). The raw data were processed to give structure factors using the Bruker SAINT program and corrected for Lorentz and polarization effects. ${ }^{7}$ For $\mathbf{1}$ and $\mathbf{2}$, the intensity data were corrected for absorption using SADABS program with multi-scan data $\left(T_{\max } / T_{\min }=0.857\right.$ for 1 and 0.885 for 2$) .{ }^{8}$ The crystal structures were solved by direct methods, ${ }^{9}$ and refined by full-matrix least-squares refinement using the SHELXL97

Table 1. Summary of the crystallographic data for $\mathbf{1}$ and $\mathbf{2}$

\begin{tabular}{|c|c|c|}
\hline & 1 & 2 \\
\hline formula & $\mathrm{C}_{27} \mathrm{H}_{36} \mathrm{Fe}_{2} \mathrm{~N}_{18} \mathrm{O}_{3}$ & $\mathrm{C}_{30} \mathrm{H}_{32} \mathrm{Fe}_{2} \mathrm{~N}_{10} \mathrm{O}_{2} \mathrm{~S}_{4}$ \\
\hline$M_{\mathrm{r}}$ & 772.44 & 804.60 \\
\hline crystal system & monoclinic & triclinic \\
\hline space group & $C 2 / c$ & $P \overline{1}$ \\
\hline$a, \AA$ & $26.047(6)$ & $8.046(3)$ \\
\hline$b, \AA$ & $9.903(2)$ & $10.464(4)$ \\
\hline$c, \AA$ & $15.661(4)$ & $11.042(4)$ \\
\hline$\alpha, \operatorname{deg}$ & 90 & $97.004(8)$ \\
\hline$\beta, \operatorname{deg}$ & $121.244(4)$ & $102.220(8)$ \\
\hline$\gamma, \operatorname{deg}$ & 90 & $102.726(7)$ \\
\hline$V, \AA^{3}$ & $3453.5(14)$ & $872.3(6)$ \\
\hline$Z$ & 4 & 1 \\
\hline$D_{\text {calc }}$, & 1.486 & 1.532 \\
\hline$T, \mathrm{~K}$ & $173(2)$ & $173(2)$ \\
\hline$\lambda, \AA$ & 0.71073 & 0.71073 \\
\hline$\mu, \mathrm{mm}^{-1}$ & 0.899 & 1.116 \\
\hline$F(000)$ & 1600 & 414 \\
\hline collected & 12080 & 6413 \\
\hline unique & 4228 & 4189 \\
\hline observed & 3150 & 2526 \\
\hline parameters & 228 & 219 \\
\hline GOF & 1.116 & 1.108 \\
\hline$R_{1}(4 \alpha \text { data })^{a}$ & 0.0436 & 0.0734 \\
\hline$w R_{2}(4 \alpha \text { data })^{b}$ & 0.1050 & 0.1888 \\
\hline
\end{tabular}

${ }^{a} R_{1}=\Sigma|| F_{\mathrm{o}}|-| F_{\mathrm{c}}|| \Sigma\left|F_{\mathrm{o}}\right| \cdot{ }^{b} w R_{2}=\left[\Sigma w\left(F_{\mathrm{o}}^{2}-F_{\mathrm{c}}{ }^{2}\right)^{2} / \Sigma w\left(F_{\mathrm{o}}\right)^{2}\right]^{1 / 2}$. computer program. ${ }^{10}$ All non-hydrogen atoms were refined anisotropically. All hydrogen atoms except for $\mathrm{CH}_{3} \mathrm{OH}$ were positioned geometrically and refined using a riding model. The crystallographic data and the result of refinements are summarized in Table 1.

\section{Results and Discussion}

Synthesis and characterization. The reaction of 1 equiv of 2,3-pyma and $\mathrm{FeCl}_{2} \cdot 4 \mathrm{H}_{2} \mathrm{O}$ and 2 equiv of $\mathrm{NaN}_{3}$ or $\mathrm{NaSCN}$ in $\mathrm{MeOH}$ solution under aerobic conditions affords the dinuclear complexes, [(2,3-pyma) $\left(\mathrm{N}_{3}\right)_{2} \mathrm{Fe}\left(\mu-\mathrm{OCH}_{3}\right)_{2} \mathrm{Fe}\left(\mathrm{N}_{3}\right)_{2}(2,3-$ pyma) $] \cdot \mathrm{CH}_{3} \mathrm{OH}$ (1) and $\left[(2,3-\right.$ pyma $)(\mathrm{NCS})_{2} \mathrm{Fe}\left(\mu-\mathrm{OCH}_{3}\right)_{2} \mathrm{Fe}$ $(\mathrm{NCS})_{2}(2,3$-pyma) $(2)$ in moderate yield, respectively. Interestingly, bis-methoxy-bridged diiron(III) compounds are obtained. As shown in X-ray crystal structures (vide infra), both iron (III) ions in $\mathbf{1}$ and $\mathbf{2}$ are connected by oxygen atoms of two methoxy groups resulted from methanol molecules, not the sought azido- or thiocyanto-bridged dinuclear complex, i.e. [(2,3pyma $) \mathrm{Fe}\left(\mu-\mathrm{N}_{3}\right)_{2} \mathrm{Fe}(2,3-$ pyma $\left.)\right]^{\mathrm{n}+}$ or $\left[(2,3-\right.$ pyma $) \mathrm{Fe}(\mu-\mathrm{NCS})_{2} \mathrm{Fe}$ $(2,3-$ pyma $)]^{\mathrm{n}+}$ dinuclear units. The compositions of $\mathbf{1}$ and $\mathbf{2}$ were determined by elemental analysis, infrared, and X-ray diffraction. The IR spectrum ( $\mathrm{KBr}$ pellet) of $\mathbf{1}$ shows $v_{\mathrm{N}=\mathrm{N}}$ of the azide ions at 2070 and $2047 \mathrm{~cm}^{-1}$ and $v_{\mathrm{NH}}$ of the 2,3-pyma at 3253 $\mathrm{cm}^{-1}$. 11 The IR spectrum (KBr pellet) of $\mathbf{2}$ shows $v_{\mathrm{C}=\mathrm{N}}$ of the thiocyanate ions at 2035 and $2012 \mathrm{~cm}^{-1}$ and $v_{\mathrm{NH}}$ of the 2,3-pyma at $3203 \mathrm{~cm}^{-1}$. ${ }^{11}$ Both compounds display the peaks corresponding to the methoxy groups at 2941, 2916, and 2818 for $\mathbf{1}$ and 2953, 2887 , and $2819 \mathrm{~cm}^{-1}$ for 2 , respectively.

$\mathrm{X}$-ray crystal structure of $\left[(2,3-\mathrm{pyma})\left(\mathrm{N}_{3}\right)_{2} \mathrm{Fe}\left(\mu-\mathrm{OCH}_{3}\right)_{2} \mathrm{Fe}\right.$ $\left(\mathbf{N}_{3}\right)_{2}$ (2,3-pyma)] $\cdot \mathbf{C H}_{3} \mathrm{OH}(\mathbf{1})$. An ORTEP drawing of $\mathbf{1}$ is shown in Figure 1 and selected bond distances and angles are listed in Table 2. The coordination geometry around iron(III) ion is a tetragonally distorted octahedron. The iron(III) ion is coordinated with two nitrogens of a 2,3-pyma, two nitrogens of two azide ions, and two oxygens of two methoxy groups. The aver-

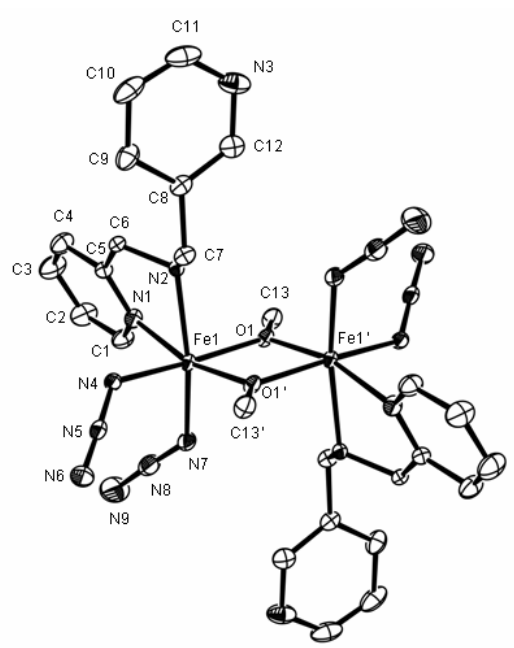

Figure 1. Structure of the $\left[(2,3-\right.$ pyma $)\left(\mathrm{N}_{3}\right)_{2} \mathrm{Fe}\left(\mu-\mathrm{OCH}_{3}\right)_{2} \mathrm{Fe}\left(\mathrm{N}_{3}\right)_{2}(2,3-$ pyma)] $\mathrm{CH}_{3} \mathrm{OH}(1)$. The atoms are represented by $30 \%$ probable thermal ellipsoids. Hydrogen atoms and $\mathrm{CH}_{3} \mathrm{OH}$ are omitted for clarity $('=$ $0.5-\mathrm{x}, 1.5-\mathrm{y}, 1-\mathrm{z})$ 
Table 2. Selected Bond Distances ( $\AA$ ) and Angles (deg) for $\mathbf{1}$ and 2

\begin{tabular}{|c|c|c|c|}
\hline \multicolumn{4}{|c|}{$\left[(2,3\right.$-pyma $)\left(\mathrm{N}_{3}\right)_{2} \mathrm{Fe}\left(\mu-\mathrm{OCH}_{3}\right)_{2} \mathrm{Fe}\left(\mathrm{N}_{3}\right)_{2}(2,3-$ pyma $\left.)\right] \cdot \mathrm{CH}_{3} \mathrm{OH}(\mathbf{1})$} \\
\hline Fe1-N1 & $2.189(3)$ & Fe1-N7 & $2.016(3)$ \\
\hline Fe1-N2 & $2.188(3)$ & Fe1-O1 & $2.005(2)$ \\
\hline Fe1-N4 & $2.018(3)$ & $\mathrm{Fe} 1-\mathrm{O} 1^{\mathrm{i}}$ & $1.974(2)$ \\
\hline $\mathrm{Fe} 1-\mathrm{Fe} 1^{\mathrm{i}}$ & $3.137(1)$ & N7-N8 & $1.169(4)$ \\
\hline N4-N5 & $1.191(4)$ & N8-N9 & $1.153(5)$ \\
\hline N5-N6 & $1.156(4)$ & $\mathrm{O} 1-\mathrm{C} 13$ & $1.422(4)$ \\
\hline N1-Fe1-N2 & $74.96(10)$ & $\mathrm{N} 2-\mathrm{Fe} 1-\mathrm{O} 1^{\mathrm{i}}$ & $94.65(9)$ \\
\hline N1-Fe1-N4 & $91.43(11)$ & N4-Fe1-N7 & $94.16(13)$ \\
\hline N1-Fe1-N7 & $93.42(12)$ & N4-Fe1-O1 & $170.88(11)$ \\
\hline N1-Fe1-O1 & $93.88(9)$ & $\mathrm{N} 4-\mathrm{Fe} 1-\mathrm{O} 1^{\mathrm{i}}$ & $97.49(11)$ \\
\hline $\mathrm{N} 1-\mathrm{Fe} 1-\mathrm{O} 1^{\mathrm{i}}$ & $165.69(10)$ & N7-Fe1-O1 & $92.93(11)$ \\
\hline N2-Fe1-N4 & $84.79(10)$ & $\mathrm{N} 7-\mathrm{Fe} 1-\mathrm{O} 1^{\mathrm{i}}$ & $97.05(11)$ \\
\hline N2-Fe1-N7 & $168.29(11)$ & $\mathrm{O} 1-\mathrm{Fe} 1-\mathrm{O} 1^{\mathrm{i}}$ & $75.92(9)$ \\
\hline N2-Fe1-O1 & $89.43(9)$ & $\mathrm{Fe} 1-\mathrm{O} 1-\mathrm{Fe} 1^{\mathrm{i}}$ & $104.08(9)$ \\
\hline \multicolumn{4}{|c|}{$\left[(2,3-\right.$ pyma $)(\mathrm{NCS})_{2} \mathrm{Fe}\left(\mu-\mathrm{OCH}_{3}\right)_{2} \mathrm{Fe}(\mathrm{NCS})_{2}(2,3$-pyma $\left.)\right](\mathbf{2})$} \\
\hline Fe1-N1 & $2.175(4)$ & Fe1-N5 & $2.063(5)$ \\
\hline Fe1-N2 & $2.228(4)$ & Fe1-O1 & $1.974(4)$ \\
\hline Fe1-N4 & $2.067(5)$ & $\mathrm{Fe} 1-\mathrm{O} 1^{\mathrm{ii}}$ & $1.999(4)$ \\
\hline $\mathrm{Fe} 1-\mathrm{Fe} 1^{\mathrm{ii}}$ & $3.141(2)$ & N5-C14 & $1.107(8)$ \\
\hline N4-C13 & $1.121(8)$ & $\mathrm{C} 14-\mathrm{S} 2$ & $1.630(8)$ \\
\hline C13-S1 & $1.607(7)$ & $\mathrm{O} 1-\mathrm{C} 15$ & $1.420(6)$ \\
\hline N1-Fe1-N2 & $75.61(16)$ & $\mathrm{N} 2-\mathrm{Fe} 1-\mathrm{O} 1^{\mathrm{ii}}$ & $89.93(15)$ \\
\hline N1-Fe1-N4 & $95.26(18)$ & N4-Fe1-N5 & $93.0(2)$ \\
\hline N1-Fe1-N5 & $90.38(18)$ & N4-Fe1-O1 & $96.16(17)$ \\
\hline N1-Fe1-O1 & $164.19(17)$ & $\mathrm{N} 4-\mathrm{Fe} 1-\mathrm{O} 1^{\mathrm{ii}}$ & $170.64(17)$ \\
\hline $\mathrm{N} 1-\mathrm{Fe} 1-\mathrm{O} 1^{\mathrm{ii}}$ & $92.16(16)$ & $\mathrm{N} 5-\mathrm{Fe} 1-\mathrm{O} 1$ & $99.88(16)$ \\
\hline N2-Fe1-N4 & $86.42(18)$ & $\mathrm{N} 5-\mathrm{Fe} 1-\mathrm{O} 1^{\mathrm{ii}}$ & $92.59(17)$ \\
\hline N2-Fe1-N5 & $165.86(16)$ & $\mathrm{O} 1-\mathrm{Fe} 1-\mathrm{O} 1^{\mathrm{ii}}$ & $75.50(16)$ \\
\hline N2-Fe1-O1 & $94.22(15)$ & $\mathrm{Fe} 1-\mathrm{O} 1-\mathrm{Fe} 1^{\mathrm{ii}}$ & $104.50(16)$ \\
\hline
\end{tabular}

Symmetry transformations used to generate equivalent atoms: (i) $0.5-\mathrm{x}$, $1.5-\mathrm{y}, 1-\mathrm{z}$; (ii) -x, -y, 1-z.

age $\mathrm{Fe}-\mathrm{N}_{2,3 \text {-pyma }}, \mathrm{Fe}-\mathrm{N}_{\text {azido, }}$ and $\mathrm{Fe}-\mathrm{O}_{\text {methoxo }}$ bond distances are 2.189(2), 2.017(2), and 1.990(1) $\AA$, respectively. The bite distance and angle of the five-membered chelate ring are 2.663(4) $\AA$ and $74.96(10)^{\circ}$, respectively. The two iron(III) ions within the dinuclear unit are connected by two methoxy groups with an inversion center. The angles of Fe1-O1-Fe1(0.5-x, 1.5-y, 1-z) and O1-Fe1-O1(0.5-x, 1.5-y, 1-z) are 104.08(9) and 75.92(9) respectively. The shortest $\mathrm{Fe} \cdots \mathrm{Fe}$ contact within the dimer is 3.137(1) $\AA$ and the shortest $\mathrm{Fe} \cdots \mathrm{Fe}$ distance between the dimers is $7.306(2) \AA$. In the structure of $\mathbf{1}$, pyridine pendant groups undergo the $\mathrm{C}-\mathrm{H} \cdots \pi$ interactions with the bridged methoxy groups, which propagate along the $c$ axis (Figure 2). For the $\mathrm{C}-\mathrm{H} \cdots \pi$ interaction, the distance between the centroid of the pyridine pendant ring and the nearest carbon atom of the methoxy group is $3.583 \AA\left(\angle \mathrm{C} 13-\mathrm{H} \cdots\right.$ centroid $\left.85.29-101.26^{\circ}\right) .^{12}$ Furthermore, the secondary nitrogen atom of 2,3-pyma forms hydrogen bonds with the uncoordinated nitrogen atom of azide

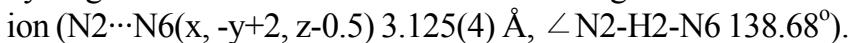

$\mathrm{X}$-ray crystal structure of $\left[(2,3-\mathrm{pyma})(\mathrm{NCS})_{2} \mathrm{Fe}\left(\mu-\mathrm{OCH}_{3}\right)_{2}\right.$

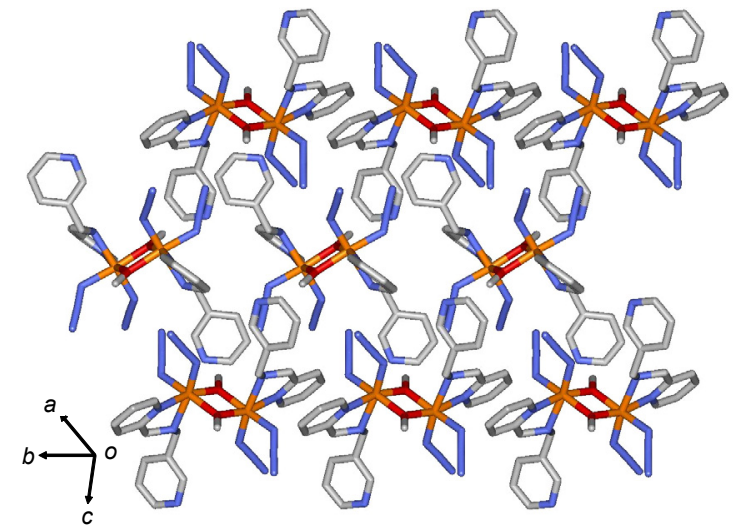

Figure 2. View of $\mathrm{CH}^{\cdots} \pi \pi$ interactions between methyl and pyridine groups in $\mathbf{1}$.

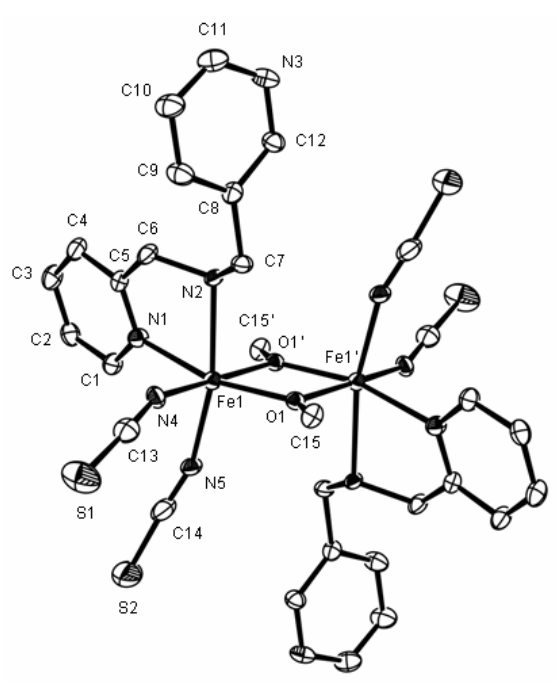

Figure 3. Structure of the $\left[(2,3-\mathrm{pyma})(\mathrm{NCS})_{2} \mathrm{Fe}\left(\mu-\mathrm{OCH}_{3}\right)_{2} \mathrm{Fe}(\mathrm{NCS})_{2}\right.$ (2,3-pyma) (2). The atoms are represented by $30 \%$ probable thermal ellipsoids. Hydrogen atoms are omitted for clarity (' $=-\mathrm{x},-\mathrm{y}, 1-\mathrm{z})$.

$\mathbf{F e}(\mathrm{NCS})_{2}$ (2,3-pyma)] (2). An ORTEP drawing of $\mathbf{2}$ is shown in Figure 3 and selected bond distances and angles are listed in Table 2. The coordination geometry around iron(III) ion is a tetragonally distorted octahedral structure. The iron(III) ion is coordinated to two nitrogens of a 2,3-pyma, two nitrogens of two thiocyanate ions, and two oxygens of two methoxy groups. The average $\mathrm{Fe}-\mathrm{N}_{2,3-p y m a}, \mathrm{Fe}-\mathrm{N}_{\text {thiocyanato, }}$ and $\mathrm{Fe}-\mathrm{O}_{\text {methoxo }}$ bond distances are 2.202(3), 2.065(4), and 1.987(3) A, respectively. The bite distance and angle of the five-membered chelate ring are 2.700(6) $\AA$ and $75.61(16)^{\circ}$, respectively. Similar to 1, the two iron(III) ions within the dinuclear unit are connected by two methoxy groups. The angles of Fe1-O1-Fe1(-x, -y, 1-z) and O1Fe1-O1(-x, -y, 1-z) are 104.50(16) and 75.50(16) ${ }^{\circ}$, respectively. The crystal structures of $\mathbf{1}$ and $\mathbf{2}$ are isomorphous. The shortest Fe $\cdots$ Fe contact within the dimer is 3.141(2) $\AA$ and the shortest $\mathrm{Fe} \cdots \mathrm{Fe}$ distance between the dimers is 8.046(3) $\AA$. In the structure of 2, two pyridine groups of the 2,3-pyma ligand experience offset $\pi-\pi$ stacking interactions with pyridine groups belonging to a neighboring dinuclear complex (Figures 4 and 5). ${ }^{12}$ For the 


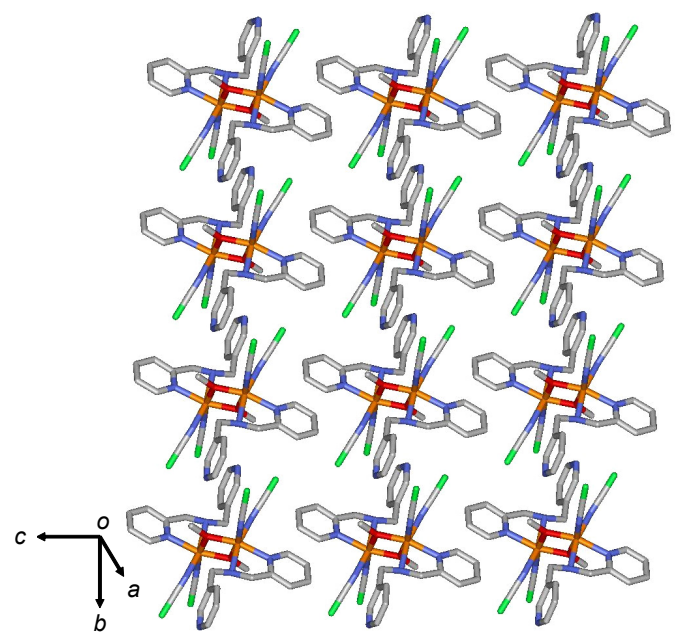

Figure 4. View of $\pi-\pi$ interactions between the coordinated pyridine groups in $\mathbf{2}$.

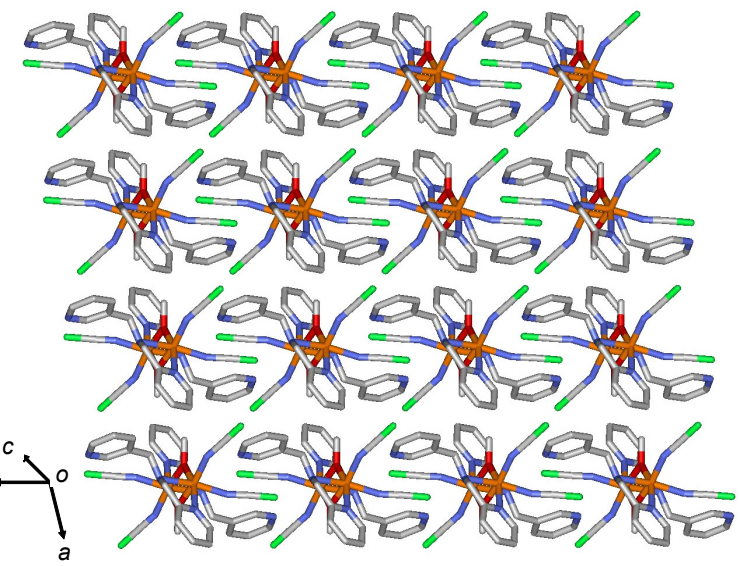

Figure 5. View of $\pi-\pi$ interactions between the pendant pyridine groups in 2 .

$\pi-\pi$ stacking interactions, the dihedral angle between two pyridine planes coordinated to iron(III) ion is $\theta=0.0 \mathrm{deg}$ and the interplanar separation of the aromatic rings is $3.36-3.38 \AA$ as well as the offset angle between the ring planes is $20.3^{\circ}$ (centroid $\cdots$ centroid $3.628 \AA$ ) (Figure 4). Additionally, the dihedral angle between the pyridine planes of pendant groups is $\theta=0.0$ deg and the interplanar separation of the aromatic rings is $3.711-3.73 \AA$ as well as the offset angle between the ring planes is $17.9^{\circ}$ (centroid $\cdots$ centroid $3.919 \AA$ ) (Figure 5). In case of $\mathbf{2}$, due to the offset $\pi-\pi$ stacking interactions, the structure becomes a two-dimensional network. In addition to, the secondary nitrogen atom of 2,3-pyma is involved in a hydrogen-bonding interaction with the nitrogen atom of pyridine pendant group (N2 $\cdots \mathrm{N} 3$ (-x, -y-1, -z+1) 3.138(7) $\left.\AA, \angle \mathrm{N} 2-\mathrm{H} 2-\mathrm{N} 3160.77^{\circ}\right)$.

Magnetic properties. Variable-temperature 5 - $300 \mathrm{~K}$ magnetic susceptibility, $\chi$, measurements on solid samples of $\mathbf{1}$ and $\mathbf{2}$ have been performed on a SQUID magnetometer (external field 5000 Oe). For complex 1, at room temperature, the effective magnetic moment, $\mu_{\text {eff }}\left[=\left(8 \chi_{M} T\right)^{1 / 2}\right]$, is $5.84 \mu_{\mathrm{B}} / \mathrm{Fe}_{2}$. This value is less than the spin-only value of $8.37 \mu_{\mathrm{B}} / \mathrm{Fe}_{2}$ expected for inde-

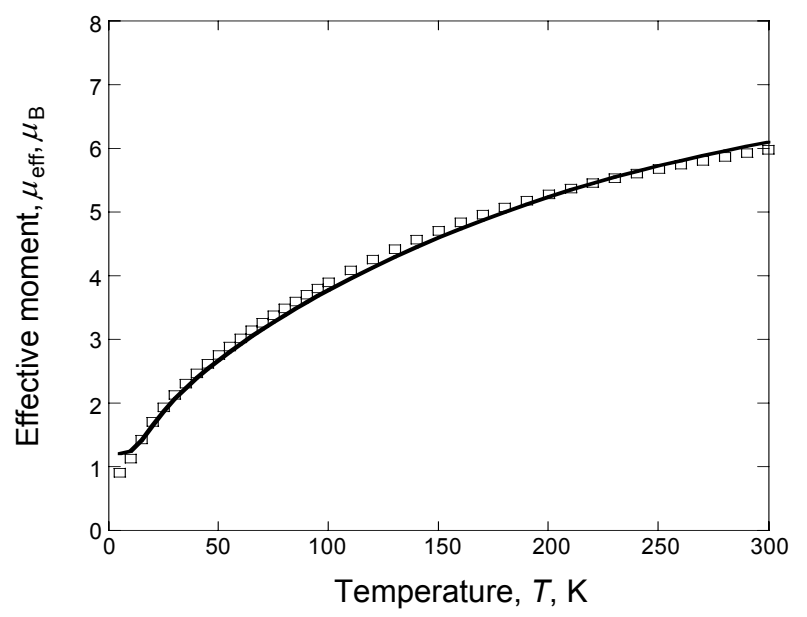

Figure 6. Fitting of effective magnetic moment versus temperature (K) data of 1 using dimer model of $S=5 / 2$ local spin. Solid line shows the best fit obtained.

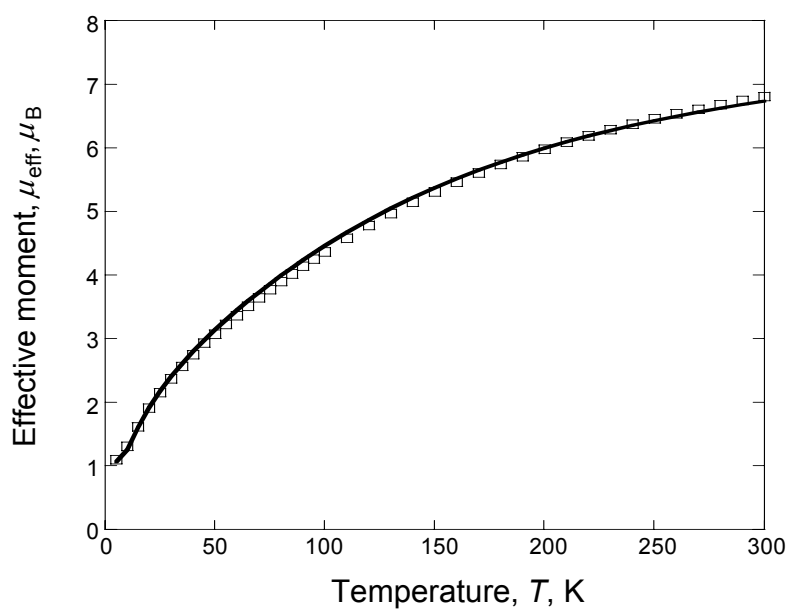

Figure 7. Fitting of effective magnetic moment versus temperature (K) data of 2 using dimer model of $S=5 / 2$ local spin. Solid line shows the best fit obtained.

pendent two $\mathrm{Fe}^{\mathrm{III}}$ spins $(g=2, S=5 / 2)$ indicative of significant antiferromagnetic coupling. $\mu_{\mathrm{eff}}(T)$ decreases with decreasing temperature (Figure 6) consistent with the presence of an antiferromagnetic interaction between the $\mathrm{Fe}(\mathrm{III})$ ions. The $\mu_{\text {eff }}(T)$ data were fit to an analytical expression for $\chi(T)$ for a coupled $S=5 / 2$ dinuclear spin model (Eq. (1)) based on the Hamiltonian $H=-2 J S_{1} \cdot S_{2}\left(S_{1}=S_{2}=5 / 2\right)$. ${ }^{13}$ The best fit to Eq. (1) had $J=-19.1 \mathrm{~cm}^{-1}, g=1.99$, and spin impurities, $\rho=0.021$.

$$
\begin{aligned}
& \chi_{\mathrm{M}}=\frac{N \beta^{2} g^{2}}{3 k T}\left[\frac{6 \exp (2 J / k T)+30 \exp (6 J / k T)+84 \exp (12 J / k T)+}{1+3 \exp (2 J / k T)+5 \exp (6 J / k T)+7 \exp (12 J / k T)}\right. \\
& \left.\frac{+180 \exp (20 J / k T)+330 \exp (30 J / k T)}{+9 \exp (20 J / k T)+11 \exp (30 J / k T)}\right](1-\rho)+2 \rho\left[\frac{N \beta^{2} g^{2}}{3 k T} S(S+1)\right]
\end{aligned}
$$

Complex 2 has a room temperature $\mu_{\text {eff }}$ of $6.68 \mu_{\mathrm{B}} / \mathrm{Fe}_{2}$. The 
Table 3. Comparison of Magnetic Properties of Diferric Complexes with Bis ( $\mu$-alkoxo) $\mathrm{Fe}_{2} \mathrm{O}_{2}$ Cores.

\begin{tabular}{lrrrr}
\multicolumn{1}{c}{ Compounds $^{a}$} & $J\left(\mathrm{~cm}^{-1}\right)$ & \multicolumn{1}{c}{$g$} & $\rho(\%)$ & Ref. \\
\hline$\left[(2,3-\right.$ pyma $)\left(\mathrm{N}_{3}\right)_{2} \mathrm{Fe}\left(\mu-\mathrm{OCH}_{3}\right)_{2} \mathrm{Fe}\left(\mathrm{N}_{3}\right)_{2}(2,3-$ pyma $\left.)\right](\mathbf{1})$ & -19.1 & 1.99 & 2.1 & this work \\
{$\left[(2,3-\right.$ pyma $)(\mathrm{NCS})_{2} \mathrm{Fe}\left(\mu-\mathrm{OCH}_{3}\right)_{2} \mathrm{Fe}(\mathrm{NCS})_{2}(2,3$-pyma $\left.)\right](2)$} & -13.9 & 2.0 & 1.6 & this work \\
$\left.\left[\mathrm{Fe}_{2}(\mathrm{dbe})_{2}(\mathrm{bz})_{2}\right]\left(\mathrm{ClO}_{4}\right)_{2}\right]$ & -20.5 & 2.05 & 0.92 & $2 \mathrm{e}$ \\
{$\left[\mathrm{Fe}_{2}(\right.$ pesd $\left.)\left(\mu-\mathrm{OCH}_{3}\right)_{2} \mathrm{Cl}_{2}\right]$} & -16.3 & 2.0 & 6.5 & $3 \mathrm{a}$ \\
{$\left[\mathrm{Fe}_{2}(\right.$ pesd $\left.)\left(\mu-\mathrm{OCH}_{2} \mathrm{CH}_{3}\right)_{2} \mathrm{Cl}_{2}\right]$} & -15.4 & 2.0 & 1.3 & $2 \mathrm{a}$ \\
{$\left[\mathrm{Fe}_{2}(\mathrm{acac})_{4}\left(\mu-\mathrm{OCH}_{2} \mathrm{CH}_{3}\right)_{2} \mathrm{Cl}_{2}\right]$} & -11.0 & 2.0 & & $2 \mathrm{a}$ \\
{$\left[\mathrm{PH}(t-\mathrm{Bu})_{3}\right]_{2}\left[\mathrm{Fe}_{2}(\mu-\mathrm{OEt})_{2} \mathrm{Cl}_{6}\right]$} & -24.6 & 2.0 & 3.2 & $3 b$ \\
\hline
\end{tabular}

$\bar{a}$ abbreviation used: $\mathrm{dbe}=2$-[bis(2-benzimidazolylmethyl)amino]ethanolato; $\mathrm{bz}=$ benzoate; pesd = 1,4-piperazinediylbis( $N$-ethylenesalicylaldiminato); acac $=$ acetylacetonato .

effective magnetic moment is lower than the spin-only value, indicative of antiferromagnetic coupling between the high-spin Fe(III) ions. Likewise 1, $\mu_{\text {eff }}(T)$ decreases with decreasing temperature (Figure 7) indicative of a strong antiferromagnetic interaction. The $\mu_{\text {eff }}(T)$ data was fit to an analytical expression for $\chi(T)$ for a coupled $S=5 / 2$ dinuclear spin model (Eq. (1)). The best fit to Eq. (1) had $J=-13.9 \mathrm{~cm}^{-1}, g=2.0$, and spin impurities, $\rho=0.016$.

It should be note that the $J$ values of $\mathbf{1}$ and $\mathbf{2}$ indicate that the methoxo groups mediate antiferromagnetic couplings between two iron(III) ions separated by $c a$. $3.14 \AA$. The coupling constants of $\mathbf{1}$ and $\mathbf{2}$ are compared with other alkoxo-bridged diiron (III) compounds in Table 3. Since the methyl group is more electron donating than hydrogen, the more negative $J$ value for methoxy-bridged Fe(III) dinuclear compound than for hydroxylbridged Fe(III) dimer observed. ${ }^{14}$ As mentioned above, complex $\mathbf{1}$ has more negative $J$ value for $\mathbf{2}$, although complexes $\mathbf{1}$ and $\mathbf{2}$ are linked by the same methoxy groups between the iron(III) ions. This can be explained by structural aspects. The bond length of Fe-Fe within the dinuclear unit in $\mathbf{1}$ is slightly shorter than that of $\mathbf{2}$ (See Table 2). Due to the short distance, the magnetic coupling of 1 can be occurred more stronger that of 2 . $^{2 a}$ Furthermore, the angles of Fe1-O1-Fe1' in $\mathbf{1}$ and $\mathbf{2}$ are 104.08(9) and $104.50(16)^{\circ}$, respectively. The latter shows slightly a larger bridging angle $c a . \sim 0.42^{\circ}$, indicative of a less negative $J$ value. ${ }^{2 \mathrm{a}, 3 \mathrm{a}}$ However, the average $\mathrm{Fe}-\mathrm{O}_{\text {methoxo }}$ bond distances for 1 and 2 are 1.990(1) and 1.987(3) $\AA$, respectively. These values are nearly similar within experimental errors. Thus this can be neglected regarding the strength of magnetic interactions. Additionally, the average $\mathrm{Fe}-\mathrm{L}_{\mathrm{N}}$ bond distance in $\mathbf{1}$ is shorter than that of 2 about $0.09 \AA$. That is, this can be facilitated to interact between the $\mathrm{Fe}$ (III) ions by an efficient electron donating character, in which the interaction in $\mathbf{1}$ will be more negative than that of $\mathbf{2}$. However, the extent of antiferromagnetic interactions in $\mathbf{1}$ and $\mathbf{2}$ is significantly smaller than for oxo-bridged $\mathrm{Fe}$ (III) complexes $\left(-J=80-120 \mathrm{~cm}^{-1}\right)$ but is comparable to those found in dihydroxo-bridged $\mathrm{Fe}(\mathrm{III})$ dinuclear compounds $(-J=$ $\left.7-17 \mathrm{~cm}^{-1}\right){ }^{15}$

\section{Conclusions}

New iron(III) dinuclear complexes bridged with methoxy groups, [(2,3-pyma) $\left(\mathrm{N}_{3}\right)_{2} \mathrm{Fe}\left(\mu-\mathrm{OCH}_{3}\right)_{2} \mathrm{Fe}\left(\mathrm{N}_{3}\right)_{2}(2,3-$ pyma $\left.)\right] \cdot \mathrm{CH}_{3}-$ $\mathrm{OH}(1)$ and $\left[(2,3-\right.$ pyma $)(\mathrm{NCS})_{2} \mathrm{Fe}\left(\mu-\mathrm{OCH}_{3}\right)_{2} \mathrm{Fe}(\mathrm{NCS})_{2}(2,3-$ pyma)] (2) have been synthesized and characterized. Both compounds are isomorphous. That is, the iron(III) ions are coordinated by two nitrogens of a 2,3-pyma, two nitrogens of two azide/ thiocyanate ions, and two oxygens of two methoxy groups. Additionally the packing structures of $\mathbf{1}$ and $\mathbf{2}$ exhibit the C-H $\cdots$ $\pi / \pi-\pi$ stacking interactions and hydrogen bonding interactions. Compounds $\mathbf{1}$ and $\mathbf{2}$ show significant antiferromagnetic couplings due to direct spin exchange via the bridged methoxy groups. The interaction in $\mathbf{1}$ is slightly stronger than that of $\mathbf{2}$.

Acknowledgments. This research was supported by Basic Science Research Program through the National Research Foundation of Korea(NRF) funded by the Ministry of Education, Science and Technology(No. 2010-0003672).

Supporting Information. Crystallographic data (excluding structure factors) for the structures reported in this paper have been deposited with the Cambridge Crystallographic Data Centre as supplementary publication nos. CCDC-790595 (for 1) and CCDC-790594 (for 2). Copies of the data can be obtained free of charge on application to CCDC, 12 Union Road, Cambridge CB2 1EZ, UK [Fax (internat.) +44-1223/336-033; Email: deposit@ccdc.cam.ac.uk].

\section{References}

1. (a) Kitagawa, S.; Kawata, S. Coord. Chem. Rev. 2002, 224, 11. (b) Tshuva, E. Y.; Lippard, S. J. Chem. Rev. 2004, 104, 987. (c) Benelli, C.; Gatteschi, D. Chem. Rev. 2002, 102, 2369. (d) Min, K. S.; DiPasquale, A. G.; Golen, J. A.; Rheingold, A. L.; Miller, J. S. J. Am. Chem. Soc. 2007, 129, 2360. (e) Zilbermann, I.; Maimon, E.; Cohen, H.; Meyerstein, D. Chem. Rev. 2005, 105, 2609. (f) Tao, J.; Maruyama, H.; Sato, O. J. Am. Chem. Soc. 2006, 128, 1790.

2. (a) Chiari, B.; Piovesana, O.; Tarantelli, T.; Zanazzi, P. F. Inorg. Chem. 1984, 23, 3398. (b) Ruiz, E.; Alemany, P.; Alvarez, S.; Cano, J. Inorg. Chem. 1997, 36, 3683. (c) Ruiz, E.; Alemany, P.; Alvarez, S.; Cano, J. J. Am. Chem. Soc. 1997, 119, 1297. (d) Ménage, S.; Que, L., Jr. Inorg. Chem. 1990, 29, 4293. (e) Han, J. H.; Shin, J. W.; Min, K. S. Bull. Korean Chem. Soc. 2009, 30, 1113.

3. (a) Chiari, B.; Piovesana, O.; Tarantelli, T.; Zanazzi, P. F. Inorg. Chem. 1982, 21, 1396. (b) Walker, J. D.; Poli, R. Inorg. Chem. 1990, 29, 756.

4. Li, F.; Wang, M.; Li, P.; Zhang, T.; Sun, L. Inorg. Chem. 2007, 46, 9364.

5. Shin, J. W.; Rowthu, S. R.; Kim, B. G.; Min, K. S. Dalton Trans. 2010, 39, 2765.

6. Soibinet, M.; Déchamps-Oliver, I.; Mohamadou, A.; Aplincourt, 
M. Inorg. Chem. Commun. 2004, 7, 405.

7. Saint Plus, v. 6.02; Bruker Analytical X-ray: Madison, WI, 1999.

8. Sheldrick, G. M. SADABS: Siemens/Bruker Area Detector Absorption Correction Program, V2.03; University of Göttingen: Germany, 2000

9. Sheldrick, G. M. Acta Crystallogr., Sect. A 1990, 46, 467.

10. Sheldrick, G. M. SHELXL 97: Program for the Crystal Structure Refinement; University of Göttingen: Germany, 1997.

11. Nakamoto, K. Infrared and Raman Spectra of Inorganic and Coordination Compounds; WILEY: New Jersey, 2009; pp 120-131.

12. (a) Desiraju, G. R. Crystal Engineering: The Design of Organic Solids; Elsevier: New York, 1989; Chap. 4. (b) Shetty, A. S.;
Zhang, J.; Moore, J. S. J. Am. Chem. Soc. 1996, 118, 1019. (c) Jennings, W. B.; Farrell, B. M.; Malone, J. F. Acc. Chem. Res. 2001, 34, 885 .

13. Kahn, O. Molecular Magnetism; VCH: New York, 1993; pp 103134.

14. Chiari, B.; Piovesana, O.; Tarantelli, T.; Zanazzi, P. F. Inorg. Chem. 1983, 22, 2781.

15. (a) Kato, M.; Yamada, Y.; Inagaki, T.; Mori, W.; Sakai, K.; Tsubomura, T.; Sato, M.; Yano, S. Inorg. Chem. 1995, 34, 2645. (b) Ghiladi, M.; Larsen, F. B.; McKenzie, C. J.; Søtofte, I.; Tuchagues, J.-P. Dalton Trans. 2005, 1687. (c) Min, K. S.; Arif, A. M.; Miller, J. S. Inorg. Chim. Acta 2007, 360, 1854. 